\title{
Dynamic Modelling and Simulation of Coal Pulverizer
}

\author{
Sumanta Basu', Sushil Cherian ${ }^{2}$ \\ ${ }^{1}$ Department of Electrical and I\&C Engineering, L\&T-MHI POWER Boilers Private Limited, Faridabad, India \\ ${ }^{2}$ Kalki Communication Technologies Pvt Ltd, Bangalore, India
}

Email address:

sumanta.basu@Intmhipower.com (S. Basu), sushil.cherian@kalkitech.com (S. Cherian)

\section{To cite this article:}

Sumanta Basu, Sushil Cherian. Dynamic Modelling and Simulation of Coal Pulverizer. International Journal of Mechanical Engineering and Applications. Vol. 9, No. 4, 2021, pp. 58-71. doi: 10.11648/j.ijmea.20210904.11

Received: August 17, 2021; Accepted: September 3, 2021; Published: September 15, 2021

\begin{abstract}
The mathematical model and simulation of coal pulverizer has been presented in the paper using first principle mass and heat balance equations based on physical insight. The coal mass flow is modelled based on the mass balance model. The pulverized coal temperature is modelled by considering the coal and the pulverized coal as a lumped thermal mass. The multi variable non-linear model is simulated in Python environment and the parameters are obtained by using the moving horizon estimation. The archived data from an operating $660 \mathrm{MW}$ coal fired boiler database are used to identify the parameters and to be compared with the model outputs. As the megawatt power output of thermal power generating plant is directly influenced by the coal being fired into the boiler, it is necessary to study the dynamic behaviour of the model as their poor dynamic performance causes a slow megawatt ramp up or ramp down rate and also causes shutdown of plant in some cases. In view of more and more penetration of renewable energy in the power grid, rapid and automatic flexible operation of coal fired boiler is necessary to accommodate injection of renewable power or withdrawal of renewable power as both remain connected directly or indirectly to the same power grid. Hence, fast response of the steam generating boiler is desired in a coal fired thermal power generating unit to generate the megawatt load as per the demand placed on the grid to maintain the power system frequency which calls for support of boiler steam flow, pressure and temperature to the steam turbine generator equipment. In order to achieve that, performance of combustion control of the boiler is one of the important factors which can be improved by modelling and implementing the predictive dynamic behaviour of coal pulverizer under varying coal feed rate in the boiler control system. The main focus of the work is to determine the pulverizer response under varying coal flow and coal characteristic condition with an objective of keeping minimum differential pressure across it based on a realistic mathematical model of pulverizer so that the boiler response can be improved under transient condition of megawatt load demand variation. The simulated model responses for various scenarios are also presented in this paper.
\end{abstract}

Keywords: DAE, NLP, NOx, HGI

\section{Introduction}

The concept of flexibility in power system is defined as the ability to operate reliably with significant shares of variable renewable electricity. In other word, it expresses the capability of a power system to maintain reliable supply in the face of rapid and large imbalances, whatever the cause. It is also interpreted as the ability to adapt to dynamic and changing conditions, for example, balancing supply and demand of electricity by the hour or minute or deploying new generation and transmission resources over a period of years. In a coal fired thermal power generating station raw coal is used as the main fuel in the steam generating boiler in addition to heavy fuel oil or light diesel oil as start-up fuel. In order to accommodating variable renewable energy in power system, flexible operation of boiler with higher megawatt load ramp rate becomes the essential need with simultaneous addressing the concerns of stable ignition and combustion of coal burner to avoid loss of flame in the furnace during minimum loading of the pulverizer, pulverizer turn down ratio and capacity, maintaining minimum pulverizer outlet temperature, avoiding pulverizer in and out of service during megawatt load ramp up or down, non-availability of design range of coal with varying $\mathrm{GCV}$, minimum volatile matter content in coal being fired etc.

Generally, the boiler time constant is in the range of five to seven minutes and there is a transportation lag from the coal feeder to the furnace which depends on the velocity in the coal 
pipes. In view of more and more penetration of renewable energy in the power grid, rapid and automatic flexible operation of coal fired boiler is necessary to accommodate injection of renewable power or withdrawal of renewable power as both remain connected directly or indirectly to the same power grid. Fast response of the steam generating boiler is desired in a coal fired thermal power generating unit to generate the megawatt load as per the demand placed on the grid to maintain the power system frequency which calls for support of boiler steam flow, pressure and temperature to the steam turbine generator equipment. Hence, the coal firing rate for actual combustion in the furnace is a major factor which affects the higher ramp rate to achieve flexible operation. In conventional combustion control, the total coal firing demand is equally distributed to all the operating pulverizers without observing the healthiness of it whether one or more pulverizer are really capable of handling the coal demand and giving full throughput to the furnace or not. In a coal fired thermal power generating station raw coal is used as the main fuel in the steam generating boiler in addition to heavy fuel oil or light diesel oil as start up fuel. Raw coal is transported on a coal conveyor belt located at the tripper floor from coal handling plant and dropped into the variable speed-controlled coal feeder for dynamic measurement of the coal being fed into the motor driven rotating coal mill called coal pulverizer also, through a central feed input pipe that uses gravity to guide the coal to fall onto a grinding table of coal pulverizer where it is crushed by electro-hydraulically operated heavy metallic rollers. Pre-heated primary air is blown from the bottom of the mill which dries up the moisturized raw coal and transport pulverized fine coal particles and air mixtures into the dynamic classifier section of the coal pulverizer. The primary airflow temperature is controlled by hot air and cold air mixing to regulate the pulverizer outlet temperature so that no fire incident happens inside coal mill or coal transporting pipes. Only the finest and lighter particles escape the vortex of dynamic rotary classifier driven by another motor and goes up to the coal burner of the boiler for combustion, whereas the rest heavier particles which hits the inside cone of the classifier and lose their velocity, falls back onto the grinding table. Accumulation of coal on the table top may reflect in to combustion of coal inside it and may damage the internal component due to high vibration. Also, due to increment in fineness of coal, stoichiometric ratio may change which will reflect in to moving of unburnt coal to second pass of the furnace and may reflect into secondary combustion of the furnace. The size distribution of the pulverized coal particles are usually required to be less than 75 micron and is determined largely by the pulverizer internal behavior and classifier settings which is not disturbed during the boiler running. The differential pressure across the pulverizer is very important to understand the dynamics of recirculating loads of pulverizer. The major measurement parameters of coal pulverizers are typically pulverizer outlet temperature, coal mass flow, primary air flow, inlet primary air temperature, motor current and pulverizer differential pressure at various MW load. Earlier works on derivation and validation of a coal pulverizer model for control has been done [1- 4]. In this paper, multi variable non-linear model is simulated in python environment and the parameters are obtained by using the moving horizon estimation to study the actual performance of the pulverizer under varying differential pressure across it as the major variable parameters of coal pulverizers.

\section{Pulverizer}

The raw coal being considered for study is having gross calorific value of $3400 \sim 4000 \mathrm{Kcal} / \mathrm{kg}$, moisture content of $12 \sim 15 \%$ at ambient temperature of $27^{\circ} \mathrm{C}$, hygroscopic index (HGI) of 45 70, volatile matter content of $16 \% \sim 22 \%$, fixed carbon of $21 \% \sim 29 \%$ and ash content of $37 \% \sim 45 \%$. The pulverizer motor rating considered is $800 \mathrm{KW}$. The total desired coal flow for each pulverizer can be calculated as the total coal flow $(\mathrm{Kg} /$ hour $)$ required to generate the megawatt load divided by the number of operating pulverizer. Each pulverizer loading can be calculated by dividing the pulverizer coal flow (kg/hour) by the pulverizer corrected capacity (kg/hour, based on moisture content, HGI, fineness). The pulverizer power consumption can be calculated under various operating parameters as (Power Consumption (KW) $=$ Motor KW Rating x [(0.9 x pulverizer loading $)+0.1]$ $\mathrm{X} 1.05$. The operating parameters under various coal and megawatt load condition are pulverizer inlet primary air temperature in the range of $254 \mathrm{DegC}$ to $282 \mathrm{DegC}$, desired constant outlet temperature of $75 \mathrm{DegC}$, pulverizer primary air flow in the range of 85.7 to 150 tons/hour and inlet primary air pressure in the range of 560 to $1100 \mathrm{mmwcl}$. The drying efficiency of pulverizer considered is in the range of $77 \%$ to $80 \%$.

The physical model of the coal pulverizer with a dynamic classifier is shown in Figure 1. Two different types of classifier- static and dynamic are found in various power plants. The static classifiers possess stationary mesh of suitably designed mesh-size to filter-out coarse/fine particles. The dynamic classifier (Figure 2) uses slow-rotating classifier-mesh, to dynamically control the particle-sizes. Large particles of the pulverized coal in the suspended mixture in separator gets discarded and falls back on the table for grinding. Lighter particles move further in classifier region. Swirling behavior of vanes of the classifier causes lighter coal particles to be thrown out of the mill according to the mesh size of classifier design and heavy particles return on the table. Only the finest and lighter particles escape the vortex of dynamic rotary classifier and goes up to the coal burner of the boiler for combustion, whereas the rest heavier particles which hits the inside cone of the classifier and lose their velocity, falls back onto the grinding table. The increase in speed of rotary classifier will increase the fineness of coal and decreases the output of pulverizer and increases coal accumulation on the pulverizer table top. The particles that drop onto the table are reground. The flow diagram of the coal pulverizing process is shown in the Figure 3 and Figure 4. 


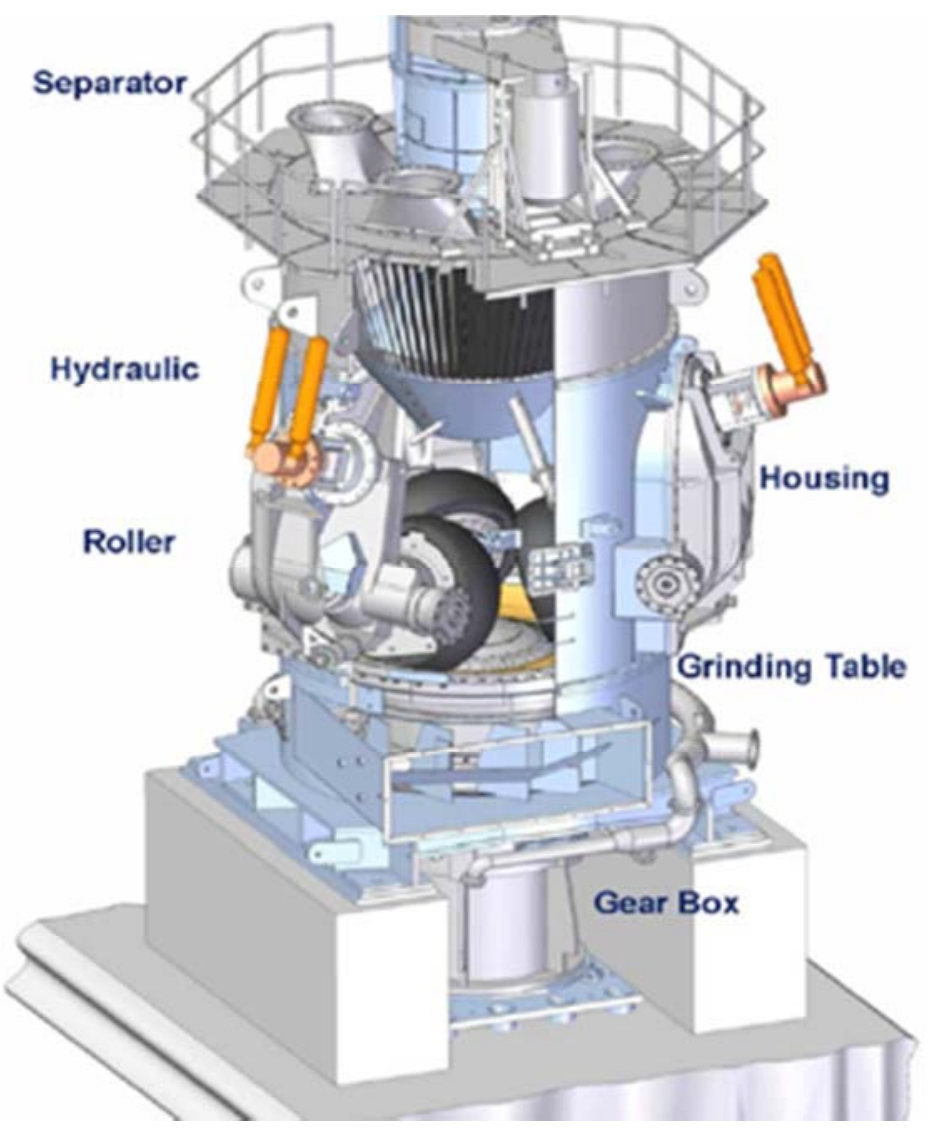

Figure 1. Coal Pulverizer.

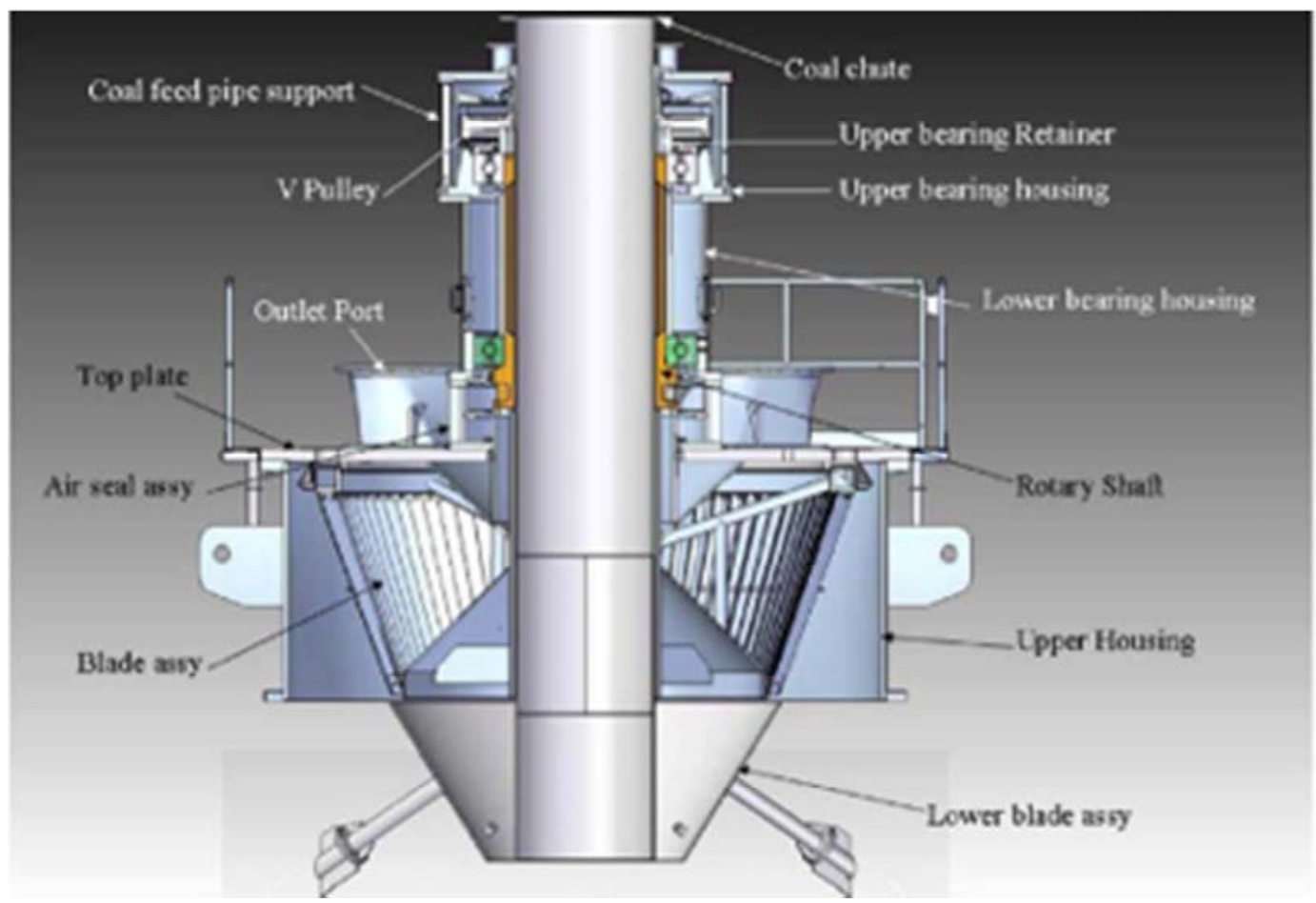

Figure 2. Coal Pulverizer Rotary Separator. 


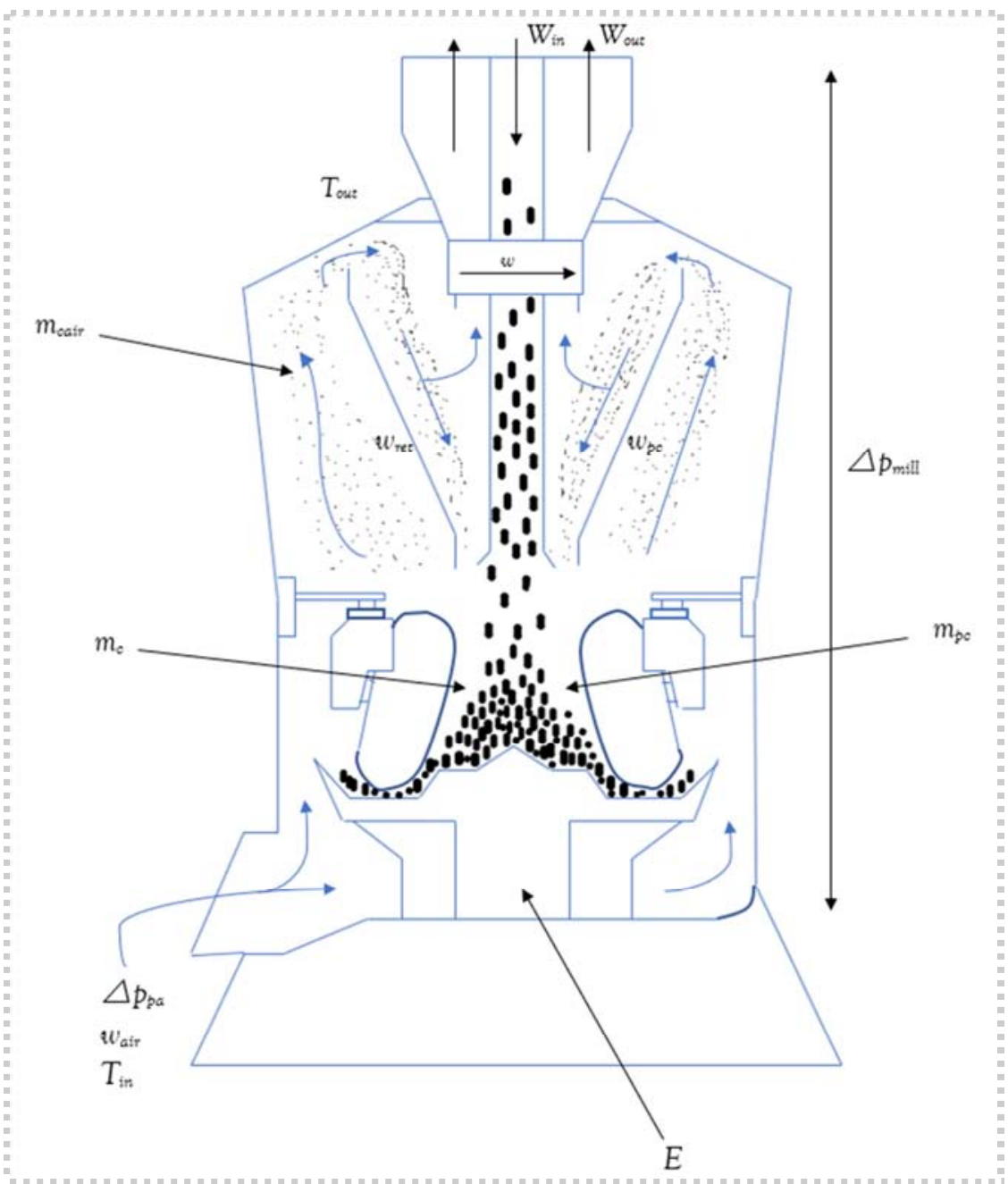

Figure 3. Coal Pulverizer Flow Diagram.

Raw coal in the bunker

- Ambient temperature $-\mathrm{T}_{\mathrm{a}}$

- Coal moisture - $\rho_{m}$

Pulverized coal out of the mill

- Outlet temperature $-\mathrm{T}_{\text {out }}$

- Moisture evaporated

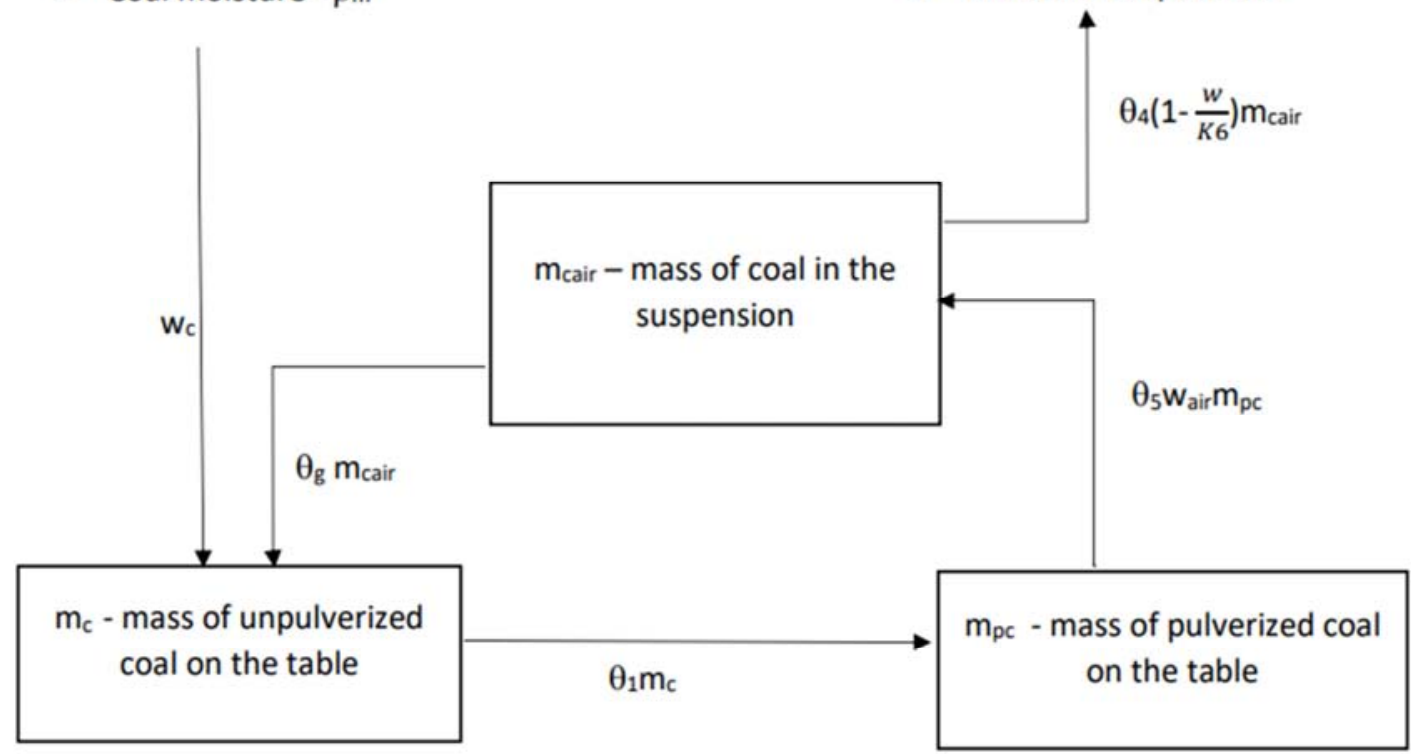

Figure 4. Coal particle circulation in pulverizer. 


\section{Mathematical Modelling}

Various earlier works has been done for the methodology of dynamic modelling of coal pulverizer $[11,12,14,15]$. The model parameters are defined in Table 1 . The mass of coal to be pulverized depends on the mass flow of the raw coal, wc, the return flow of the particles rejected by the classifier, wret, and the grinding rate which is proportional to the mass of raw coal on the grinding table, $\mathrm{m}_{\mathrm{c}}$.

$$
\frac{d}{d t} m_{c}(t)=w_{c}(t)+w_{r e t}(t)-\theta_{1} m_{c}(t)
$$

Table 1. Parameter Definition.

\begin{tabular}{lll}
\hline Sl no & Description & Symbol \\
\hline 1 & Mass of unground coal on the table $(\mathrm{kg})$ & $m_{C}$ \\
2 & Mass of pulverized coal on the table $(\mathrm{kg})$ & $m_{p c}$ \\
3 & Mass of pulverized coal carried by primary air $(\mathrm{kg})$ & $m_{\text {cair }}$ \\
4 & Mass flow of the dry raw coal to the mill $(\mathrm{kg} / \mathrm{s})$ & $w_{C}$ \\
5 & Mass flow of pulverized coal $(\mathrm{kg} / \mathrm{s})$ & $w_{p c}$ \\
6 & Mass flow of pulverized coal out of the mill $(\mathrm{kg} / \mathrm{s})$ & $w_{\text {out }}$ \\
7 & Mass flow of coal returning to the table $(\mathrm{kg} / \mathrm{s})$ & $w_{\text {ret }}$ \\
8 & Primary air mass flow $(\mathrm{kg} / \mathrm{s})$ & $w_{\text {air }}$ \\
9 & Primary air differential pressure $(\mathrm{mbar})$ & $\Delta P_{\text {air }}$ \\
10 & Primary air inlet temperature $\left({ }^{\circ} \mathrm{C}\right)$ & $T_{i n}$ \\
11 & Classifier temperature $($ outlet temperature $)\left({ }^{\circ} \mathrm{C}\right)$ & $T_{\text {out }}$ \\
12 & Pressure drop across the mill $(\mathrm{mbar})$ & $\Delta P_{\text {mill }}$ \\
13 & Power consumed for grinding $(\%)$ & $\mathrm{E}$ \\
14 & Power consumed for running empty mill $(\%)$ & $E_{e}$ \\
15 & Coal moisture $(\%)$ & $\rho_{m}$ \\
16 & Classifier speed (rpm) & $\omega$ \\
17 & Latent heat of vaporization $(\mathrm{J} / \mathrm{kg})$ & $L_{v}$ \\
18 & Specific heat of air $\left(\mathrm{J} /\left(\mathrm{kg}{ }^{\circ} \mathrm{C}\right)\right)$ & $C_{\text {air }}$ \\
19 & Specific heat of water $\left(\mathrm{J} /\left(\mathrm{kg}{ }^{\circ} \mathrm{C}\right)\right)$ & $C_{W}$ \\
20 & Specific heat of coal $\left(\mathrm{J} /\left(\mathrm{kg}{ }^{\circ} \mathrm{C}\right)\right)$ & $C_{C}$ \\
21 & Optimal model parameters $(\mathrm{i}=1$ to 11$)$ & $\Theta_{\mathrm{i}}$ \\
\hline
\end{tabular}

The mass of pulverized coal on the table, mpc, depends on the grinding rate and the amount of coal picked up by the primary air from the table, wpc.

$$
\frac{d}{d t} m_{p c}(t)=\theta_{1} m_{c}(t)-w_{p c}(t)
$$

The mass of particles in the pneumatic transport upwards in the mill, mcair, depends on the mass flow of coal particles picked up from the grinding table, the fuel flow out of the mill, wout, and the return flow of rejected particles to the table.

$$
\frac{d}{d t} m_{\text {cair }}(t)=W_{p c}(t)-W_{\text {out }}(t)-W_{\text {ret }}(t)
$$

The mass flow of pulverized particles picked up by the primary air flow, w air, to be transported towards the classifier is proportional to the primary air mass flow and the mass of pulverized coal on the table.

$$
W_{p c}(t)=\theta_{5} W_{\text {air }}(t) m_{p c}(t)
$$

The mass flow of pulverized coal out of the mill is proportional to the mass of coal lifted from the table and depends on the classifier speed, $\omega$

$$
W_{\text {out }}(t)=\theta_{4} m_{\text {cair }}(t)\left(1-\frac{\omega(t)}{\theta_{6}}\right)
$$

where $0<\omega(\mathrm{t})<\theta 6 . \theta 6$ has the same unit as $\omega$, making the term $\left(1-\omega(t) / \theta_{6}\right.$ a dimensionless rating factor.

The mass flow of coal returning to the grinding table is proportional to the mass of coal in the pneumatic transport $m_{\text {cair. }}$

$$
W_{\text {ret }}(t)=\theta_{9} m_{\text {cair }}(t)
$$

The pressure drops, $\Delta P_{\text {mill }}$, across the mill depends on the differential pressure of the primary air, $\Delta P_{\text {air }}$, and the amount of coal suspended in the air. During normal operation, the mill pressure drop is predominately proportional to the primary air differential pressure and a small change in coal mass does not affect the pressure drop significantly. Also, when the coal mass becomes zero, the pressure drop also becomes zero. These conditions are guaranteed by the term $\left(1-e^{-\theta 8(t)}\right) \varepsilon$ $(0,1)$.

$$
\Delta P_{\text {mill }}(t)=\theta_{7}\left(1-e^{-\theta_{8} m_{\text {cair }} \omega(t)}\right) \Delta P_{\text {air }}(t)
$$

The power consumed for grinding is a sum of the power needed for rolling over raw and ground coal and the constant power need for running an empty mill $(\mathrm{Ee})$.

$$
E(t)=\theta_{2} m_{p c}(t)+\theta_{3} m_{c}(t)+E_{e}
$$

Finally, the temperature equation is based on first principles (under the assumptions given above). The significant heat contribution comes from the primary air, moisture and coal flow into the mill $\left(C_{\text {air }} W_{\text {air }}(t)(t), \rho_{m} W_{C}(t), C_{C} W_{C}(t)\right)$, and from grinding $\left(\theta_{10} E(t)\right)$. The heat is used to evaporate moisture $((\mathrm{t}))$ and raise the temperature of the coal and mill chassis to the outlet temperature $\left(C_{\text {air }} W_{\text {air }}(t) T_{\text {out }}(t), C_{C}\right.$ $\left.W_{\text {out }}(t) T_{\text {out }}(t)\right)$

$$
\begin{gathered}
\frac{d}{d t} T_{\text {out }}(t)=\frac{1}{\theta_{11}}\left[C_{\text {air }} W_{\text {air }}(t) T_{\text {in }}(t)+\rho_{m} C_{w} W_{c}(t) T_{a}+\right. \\
C_{c} W_{c}(t) T_{a}-C_{\text {air }} W_{\text {air }}(t) T_{\text {out }}(t)- \\
\left.C_{c} W_{\text {out }}(t) T_{\text {out }}(t)-\rho_{m} W_{c}(\mathrm{t}) L_{v}+\theta_{10} E(t)\right]
\end{gathered}
$$

The resulting model is a fourth order nonlinear model of the form

$$
\begin{aligned}
\frac{d x(t)}{d t} & =f(x(t), u(t)) \\
y(t) & =h(x(t), u(t))
\end{aligned}
$$

With

$x(t)=\left[\begin{array}{c}m_{c}(t) \\ m_{\text {pc }}(t) \\ m_{\text {cair }}(t) \\ T_{\text {out }}(t)\end{array}\right], u(t)=\left[\begin{array}{c}\omega(t) \\ \Delta P_{\text {air }}(t) \\ W_{\text {air }}(t) \\ T_{\text {in }}(t) \\ W_{c}(t)\end{array}\right], y(t)=\left[\begin{array}{c}W_{\text {out }}(t) \\ \Delta P_{\text {mill }}(t) \\ E(t) \\ T_{\text {out }}(t)\end{array}\right]$

and 11 tuning parameters $\theta 1, \ldots, \theta 11$. 


\section{Parameter Estimation Methodology with Actual Plant Operating Data}

Moving Horizon Estimation (MHE) is an optimization approach that uses a series of measurements observed over time, containing noise (random variations) and other inaccuracies. It produces estimates of unknown variables or parameters. Unlike deterministic approaches like the Kalman filter, MHE requires an iterative process that relies on linear programming or nonlinear programming solvers to find a solution. In addition to this, increased interest in MHE has resulted from its proven superiority over traditional estimation approaches of the extended Kalman filter [5]. The main practical advantages of MHE is that it allows to handle complex nonlinear dynamic models directly and to incorporate constraints. MHE is used to estimate the measured or unmeasured states of dynamical systems in general. MHE adjusts the model's initial circumstances and parameters to match measured and projected values. MHE is based on the optimization of a process model and observations over a finite horizon. At time $t$, the present process state is sampled, and a minimizing strategy for a relatively short time horizon in the past is determined (through a numerical minimization algorithm): [t-T,t]. Specifically, an online or on-the-fly calculation is used to explore state trajectories that find (via the solution of EulerLagrange equations) an objective-minimizing strategy until time t. Only the last step of the estimation strategy is used, then the process state is sampled again and the calculations are repeated starting from the time-shifted states, yielding a new state path and predicted parameters. The estimation horizon keeps being shifted forward and for this reason the technique is called moving horizon estimation. Although this approach is not optimal, in practice it has given very good results when compared with the Kalman filter and other estimation strategies. The application of MHE is generally to estimate measured or unmeasured states of dynamical systems. Initial conditions and parameters within a model are adjusted by MHE to align measured and predicted values. MHE is based on a finite horizon optimization of a process model and measurements. Moving horizon estimation (MHE) is a multivariable estimation algorithm that uses:

1) an internal dynamic model of the process

2) a history of past measurements and

3) an optimization cost function $J$ over the estimation horizon,

4) to calculate the optimum states and parameters.

The MHE calculates the average value of past data that have been sampled at a specified interval. A sliding window with $\mathrm{M}$ steps back from the actual time instance (tk), is considered. In every sample step (Ts), this window is shifted one-step ahead-in Figure 5, this is illustrated for one measurement variable, ym. At the filter initialization (t0), only one measurement is available, and therefore the measurement storage must be filled with $\mathrm{r}<\mathrm{M}$ steps before the window starts to move. Afterwards, the window length is kept constant, and all the past $\mathrm{M}$ measurements are considered (the window with
$\mathrm{M}$ measurements is colored in green in the Figure 5 below).

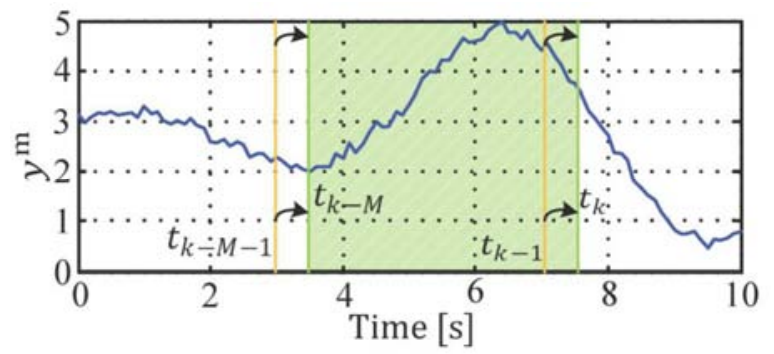

Figure 5. Schematic Representation of Estimation Horizon.

The concept of parameter estimation with MHE optimization has been applied for the pulverizer model under consideration $[3,5,13]$. It is implemented in Python language using the "SciPy" library. It provides many user-friendly and efficient numerical routines, such as routines for numerical integration, interpolation, optimization, linear algebra, and statistics.

\subsection{Parametric Properties of the MHE Problem}

Tuning of the mathematical model typically involves adjustment of objective function terms or constraints that limit the rate of change, penalize the rate of change, or set absolute bounds [10]. Measurement availability is indicated. The optimizer can also include or exclude a certain adjustable parameter or manipulated variable. Another important tuning consideration is the time horizon length. Including more points in the time horizon allows the estimator to reconcile the model to more data. In a typical power plant studied in this paper consist of total eight coal pulverizers (numbered as A, B, $\mathrm{C}, \mathrm{D}, \mathrm{E}, \mathrm{F}, \mathrm{G}, \mathrm{H}$ ) and only six normally remain in operation for full $660 \mathrm{MW}$ operation under design coal.

Lower and upper parameters bounds are declared as follows:

Table 2. Parameter Bounds.

\begin{tabular}{lll}
\hline Parameter & LB & UB \\
\hline$\theta 1$ & 0.02 & 0.05 \\
$\theta 2$ & 0.01 & 0.06 \\
$\theta 3$ & 0.04 & 0.085 \\
$\theta 4$ & 0.7 & 0.91 \\
$\theta 5$ & 0.001 & 0.005 \\
$\theta 6$ & 0.5 & 3 \\
$\theta 7$ & 3 & 5 \\
$\theta 8$ & 0.05 & 0.2 \\
$\theta 9$ & 0.3 & 0.6 \\
$\theta 10$ & 3 & 15 \\
$\theta 11$ & 4230000 & 4400000 \\
\hline
\end{tabular}

The solver used is IPOPT. It minimizes the sum of the absolute value of the difference between the $\mathrm{CV}$ and the set point. Maximum number of major iterations for solution by the solver is 260 .

The feedback status is set to zero (means the measurement should not be used either in estimation or in updating a parameter in the model) for all 11 parameters $(\theta 1-\theta 11)$, Wout, Delpmill and Energy consumption (E) except Tout. 
1) All $11(\theta 1-\theta 11)$ parameters are configured such that optimizer can adjust the values for same. Input and output variables are not allowed to be adjusted by the optimizer.

2) Maximum that a manipulated can move each cycle $1.0 \mathrm{e} 20$

3) Cost function is set to minimization.
The measurement gap defines a dead-band region around the measurement. If the model prediction is within that dead-band, there is no objective function penalty. The value of this measurement gap is set to 1 .

The objective function value of this MHE problem over each iteration is plotted as above in Figure 6.

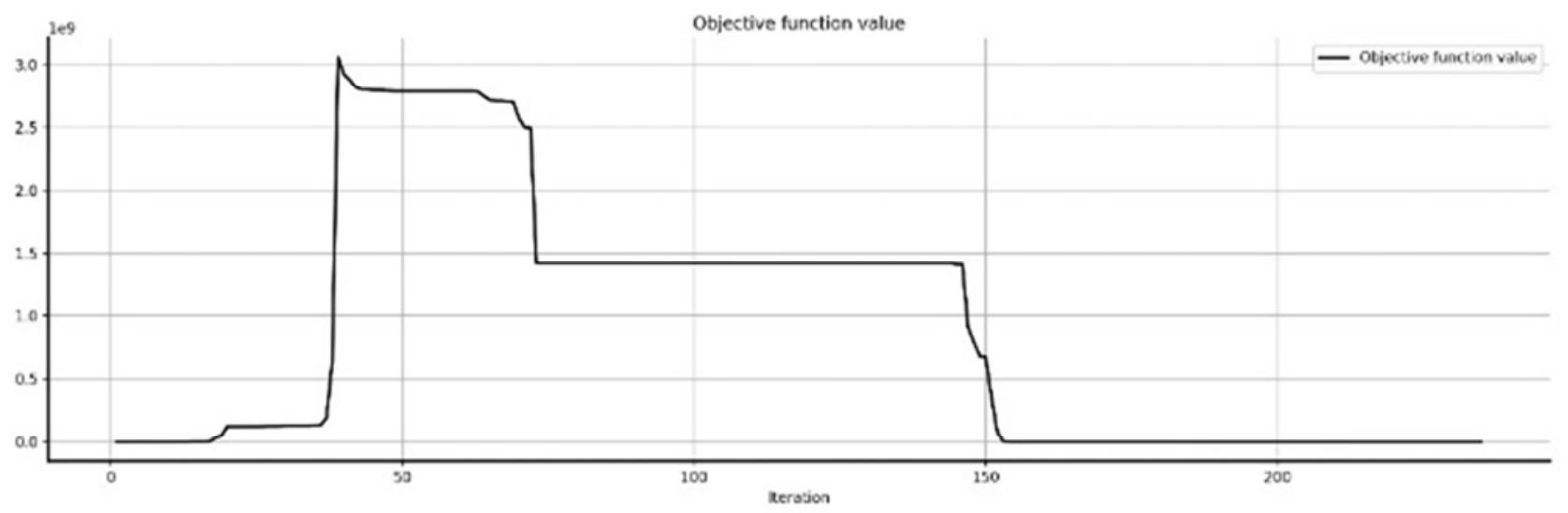

Figure 6. Objective Function Values.

Actual plant operating data of pulveriser number $\mathrm{E}$ with date range from 14-10-2020 00:04 Hrs to 14-10-2020 23:59 Hrs is used to perform parameter estimation. There are 250 data points at approximately 6 min intervals. Plots of the measured data are given in Figures 7, 8, and 9.

1) Specific heat capacity of air, moisture, and coal (Cair, $C w$, , coal inlet temperature $(\mathrm{Ta})$, moisture content in coal $(\rho m)$ and latent heat of vaporisation $(\mathrm{Lv})$ is assumed to be constant as referred from the pulverizer design document parameters.

2) Coal mill DP ( $\triangle P$ mill) is calculated as the measured difference between coal pulverizer $\mathrm{E}$ lower house pressure and outlet pressure.
3) Classifier speed $(\omega)$ is calculated using Coal flow v/s classifier speed function curve available in the design document.

4) Power consumed for running empty mill is calculated by using the measured mill current.

5) Both $\mathrm{E}$ and $\mathrm{E}_{\mathrm{e}}$ are calculated as the percentage of the Mill power consumption at $\mathrm{t} 100 \%$ mill loading.

6) Pulverised coal flow rate $\left(\mathrm{W}_{\mathrm{Out}}\right)$ is assumed to be uniformly distributed between $99.9 \%$ - 100\% of Coal feeder flow rate $\left(\mathrm{W}_{\mathrm{c}}\right)$

7) The model accounts for the effect of moisture variation in coal also.
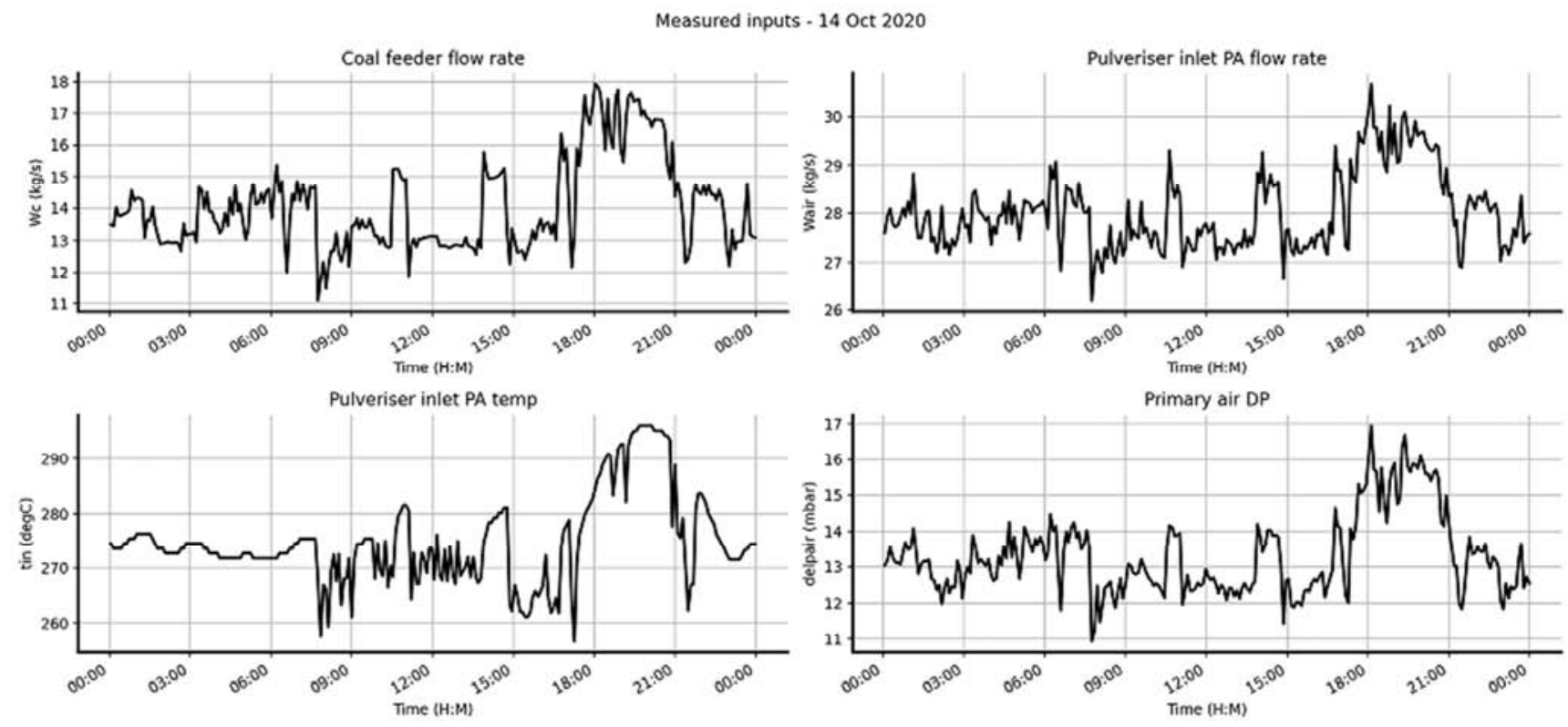

Figure 7. Measured data for Model inputs - (WC, Wair, Tin, APair). 


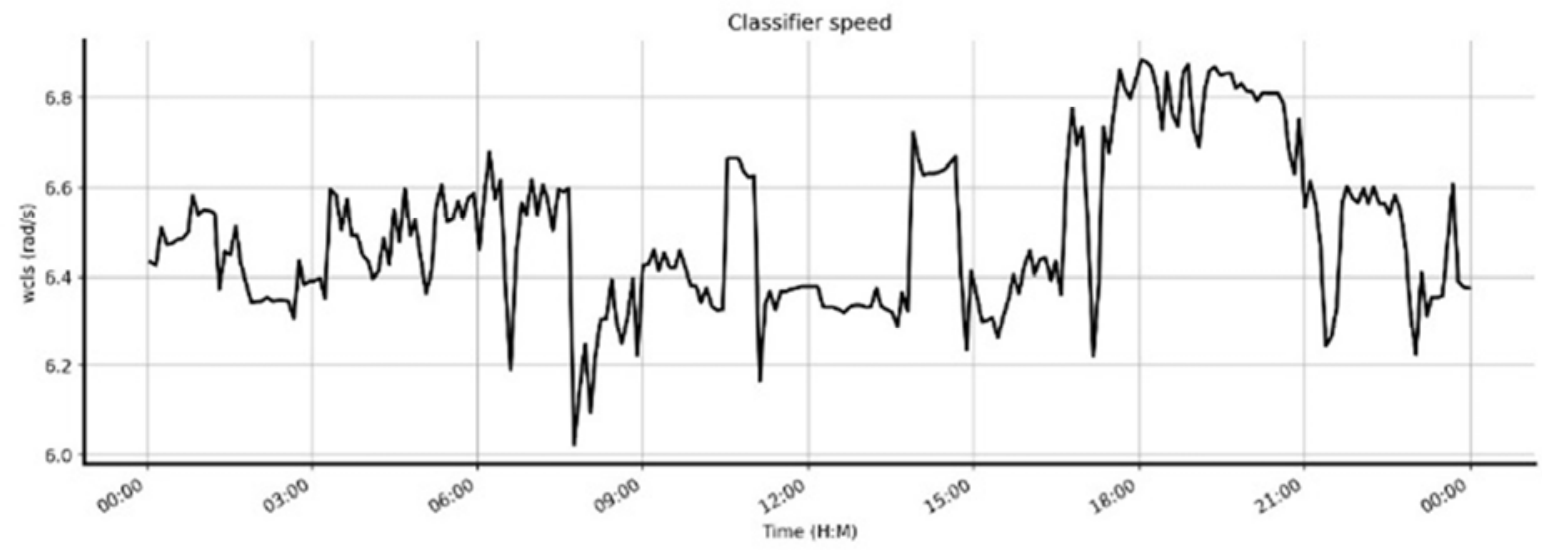

Figure 8. Model inputs $-\omega$.
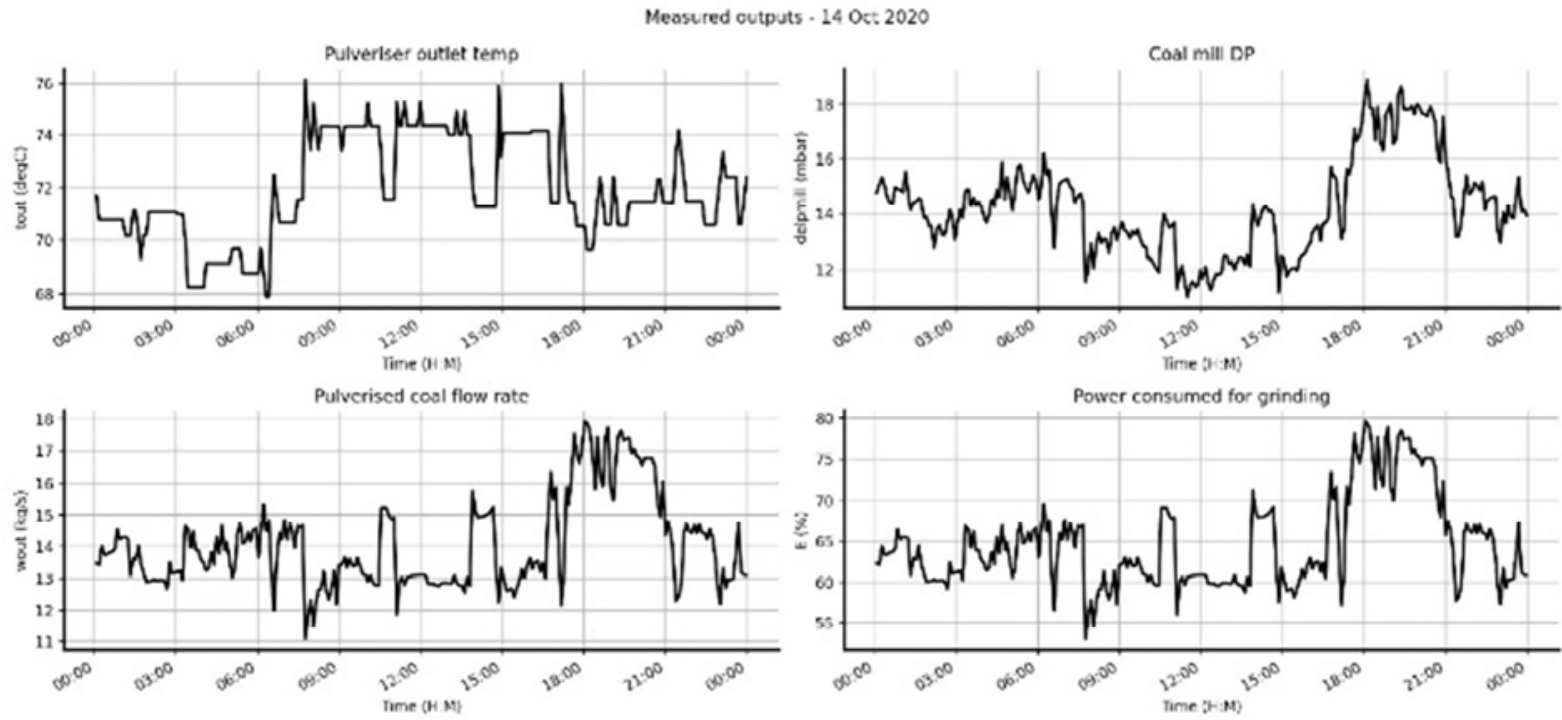

Figure 9. Measured data for Model outputs - (Tout, Wout, $\triangle$ Pmill, E).

Table 3. Model Constants- (Ta, $\rho m, L v, E e)$.

\begin{tabular}{ll}
\hline Constants & Value \\
\hline $\mathrm{T}_{a}$ & 27 \\
$\rho_{\text {in }}-\rho_{\text {out }}$ & 10.9 \\
$\mathrm{~L}_{v}$ & 2260000 \\
$\mathrm{E}_{e}$ & 25 \\
$\mathrm{C}_{\text {air }}$ & 718 \\
$\mathrm{C}_{W}$ & 4184 \\
$\mathrm{C}_{C}$ & 1260 \\
\hline
\end{tabular}

From the actual plant operating data, parameters of the pulveriser number $\mathrm{E}$ are estimated as follows.

Table 4. Parameter estimated for Pulverizer.

\begin{tabular}{lll}
\hline Parameters & Pulveriser E parameters & Unit \\
\hline$\theta_{1}$ & 0.0312 & $\mathrm{~s}^{-1}$ \\
$\theta_{2}$ & 0.0100 & $\mathrm{~kg}^{-1}$ \\
$\theta_{3}$ & 0.0850 & $\mathrm{~kg}^{-1}$ \\
$\theta_{4}$ & 0.9100 & $\mathrm{~s}^{-1}$ \\
$\theta_{5}$ & 0.0016 & $\mathrm{~kg}^{-1}$ \\
$\theta_{6}$ & 0.9624 & $\mathrm{rad} / \mathrm{s}$ \\
$\theta_{7}$ & 5.0000 & \\
$\theta_{8}$ & 0.0721 & $\mathrm{~kg}^{-1}$ \\
$\theta_{9}$ & 0.3000 & $\mathrm{~s}^{-1}$ \\
$\theta_{10}$ & 3.0000 & $\mathrm{~J} \mathrm{~s}^{-1}$ \\
$\theta_{11}$ & 4230000 & ${ }^{\circ} \mathrm{C} / \mathrm{J}$ \\
\hline
\end{tabular}

\subsection{Simulation Methodology}

Dynamic model equations are given in the continuous time form as differential algebraic equations (DAE). Solution of the system of DAE is based on orthogonal collocation on finite elements which is a direct, simultaneous, full discretization approach. The continuous time variables are discretized to transform the infinite-dimensional optimal control problem to a finite dimensional nonlinear programming (NLP) problem. Both the control inputs and the states are discretized. The full discretization is realized with orthogonal collocation on finite elements. It is implemented in Python language using the "SciPy" library. It provides many user-friendly and efficient numerical routines, such as routines for numerical integration, interpolation, optimization, linear algebra, and statistics.

\subsection{Simulation Result}

The pulveriser E model output as compared to its measured values is as shown in figure 10. The simulation result shows that the predicted model output resembles with the actual measured values from the operating plant. 

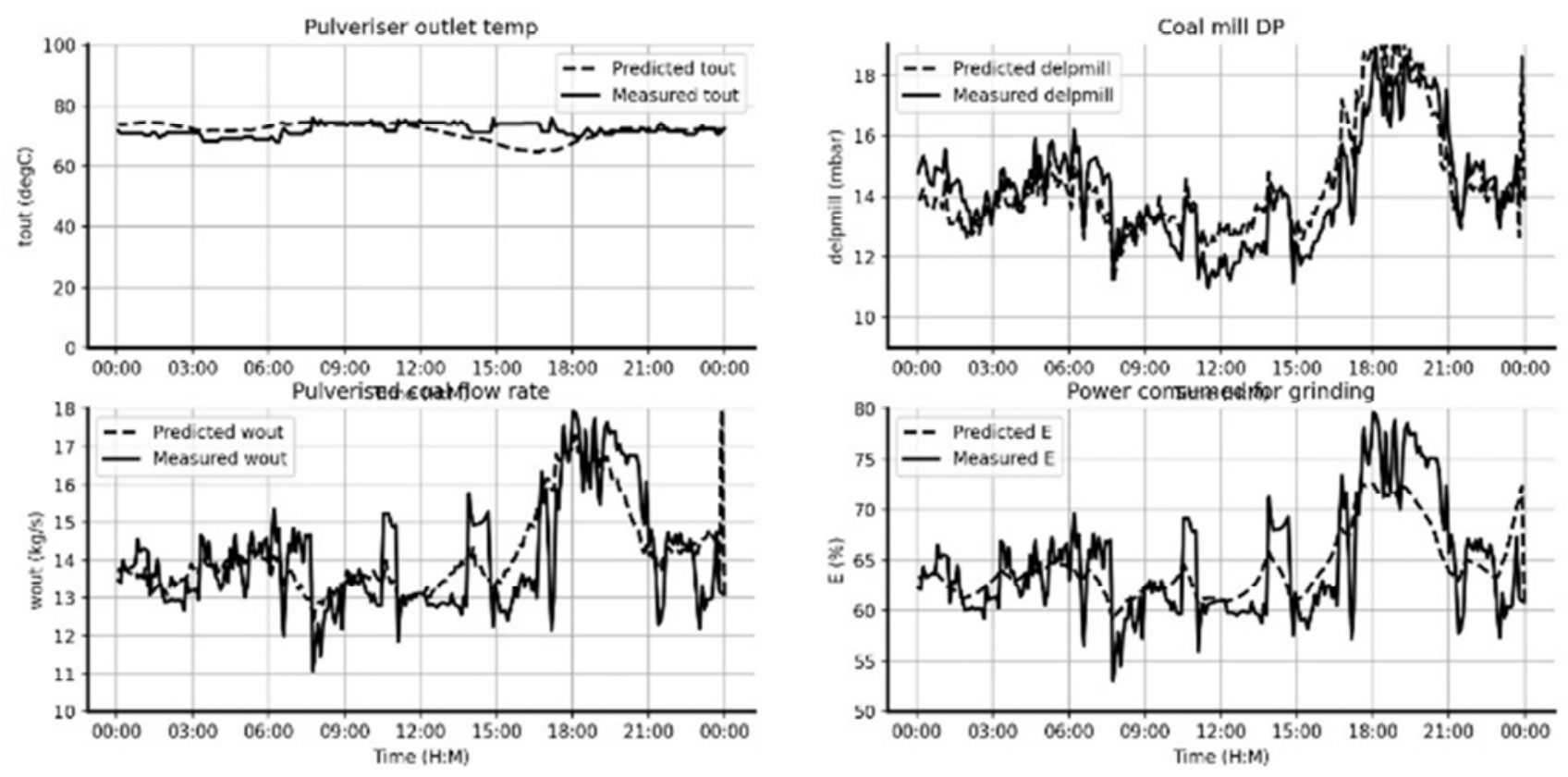

Figure 10. Predicted and Measured data for Model outputs - $\left(T_{\text {out }}, W_{\text {out }}, \Delta P_{\text {mill }}, E\right)$.

\section{Optimization of Pulverizer Loading}

A method to optimize loading of coal pulveriser system is proposed and several test cases are performed to validate the method. It is ensured that the total coal demand for full 660 MW under design coal condition is met. The nominal capacity $(90.70 \mathrm{Kg} / \mathrm{Hr})$ and corrected capacity $(83.50 \mathrm{Kg} / \mathrm{Hr}$, based on moisture content, HGI, fineness) of each pulverizer shall not be crossed while loading more the healthy one in case of degradation of other operating pulverizer wherein loading becomes less. Six operating pulverizers as $-\mathrm{A}, \mathrm{B}, \mathrm{C}, \mathrm{D}, \mathrm{E}, \mathrm{F}$ are considered for the same. The problem is formulated as a steady state linear programming problem. Relation between Primary air flow rate versus its pulverizer DP and Primary air flow rate versus pulverizer outlet coal flow rate are established for each of the coal pulverizer A, B, C, D, E and F using linear regression analysis as shown in Figure 11 below. These curves are based on historical data of the mills as well as dynamic modelling of the pulverizer. Mill B is assumed to be degraded. Hence its Delpmill v/s Wair is made not to coincide with rest of the operating pulveriser.

Wout v/s Wair curve of mill A, B, C, D, E, F are made identical to each other. This relationship between Wout and Wair is not directly introduced into the optimization problem as a constraint. Instead, it is considered for calculated the Total Wair demand corresponding to the total coal demand. And, for calculating the Mill outlet coal flow in each mill from its optimized Wair.

$$
\text { Total } W_{\text {air }}=\mathrm{f}\left(\text { Total } W_{\text {out }}\right)
$$

The total sum of DP of all coal mill is set as the objective function and this is to be minimized. Simplex LP algorithm is used for the optimization.

Objective function to minimize is $\left(\Delta P_{\text {mill, } A}+\Delta P_{\text {mill, } B}+\right.$ $\left.\Delta P_{\text {mill }, C}+\Delta P_{\text {mill }, D}+\Delta P_{\text {mill }, E}+\Delta P_{\text {mill }, F}\right)$, Where, $\Delta P_{\text {mill }}=$ $\mathrm{f}\left(W_{\text {air }}\right)$.

The objective function is subjected to a few constraints. Appropriate assumptions are made for maximum and minimum primary air flow rate. The total primary air flow rate in all coal mill is set equal to the total primary air needed to meet the total coal demand.

The upper bound of $W_{\text {air }}$ in each mill are estimated dynamically. Based on HGI, fineness and moisture (obtained from pulveriser design data) and the corrected capacity of each mill is estimated based on the following formula:

Corrected Capacity $=$ Nominal capacity $* K_{h} * K_{f} * K_{m}$

Where,

$K_{h}$ - Mill capacity correction factor due to HGI $=1.000$

$K_{f}$ - Mill capacity correction factor due to fineness $=0.985$

$K_{m}$ - Mill capacity correction factor due to moisture $=0.935$

From the corrected capacity of each mill, upper bound for $W_{\text {air }}$ is calculated based on the $W_{\text {air }} \mathrm{v} / \mathrm{s} W_{\text {out }}$ curve mentioned above in Figure 12. $W_{\text {air }}$ corresponding to Nominal mill capacity is 159.5 and the same was corrected to be 147.55 .

Bounds: $80<W_{\text {air }, A}<147.55$

$80<W_{\text {air }, B}<147.55$

$80<W_{\text {air }, C}<147.55$

$80<W_{\text {air }, D}<147.55$

$80<W_{\text {air }, E}<147.55$

$80<W_{\text {air }, F}<147.55$

Initial values:

$W_{\text {air }, A}-$ Total primary air required / 6 
$W_{\text {air }, B}$ - Total primary air required / 6

$W_{\text {air }, C}$ - Total primary air required / 6

$W_{\text {air }, D}$ - Total primary air required / 6

$W_{\text {air }, E}$ - Total primary air required / 6

$W_{\text {air }, F}$ - Total primary air required / 6

Constraints:
Simulation Result of Optimized Model of Pulverizer

Total coal demand is kept constant (350 Tons per hour) and three different cases are simulated as follows.

1) No pulverizer is degraded.

2) One pulverizer is degraded.

3) Two pulverizers are degraded.

$W_{\text {air }, A}+W_{\text {air }, B}+W_{\text {air }, C}+W_{\text {air }, D}+W_{\text {air }, E}+W_{\text {air }, F}=$

Total primary air required

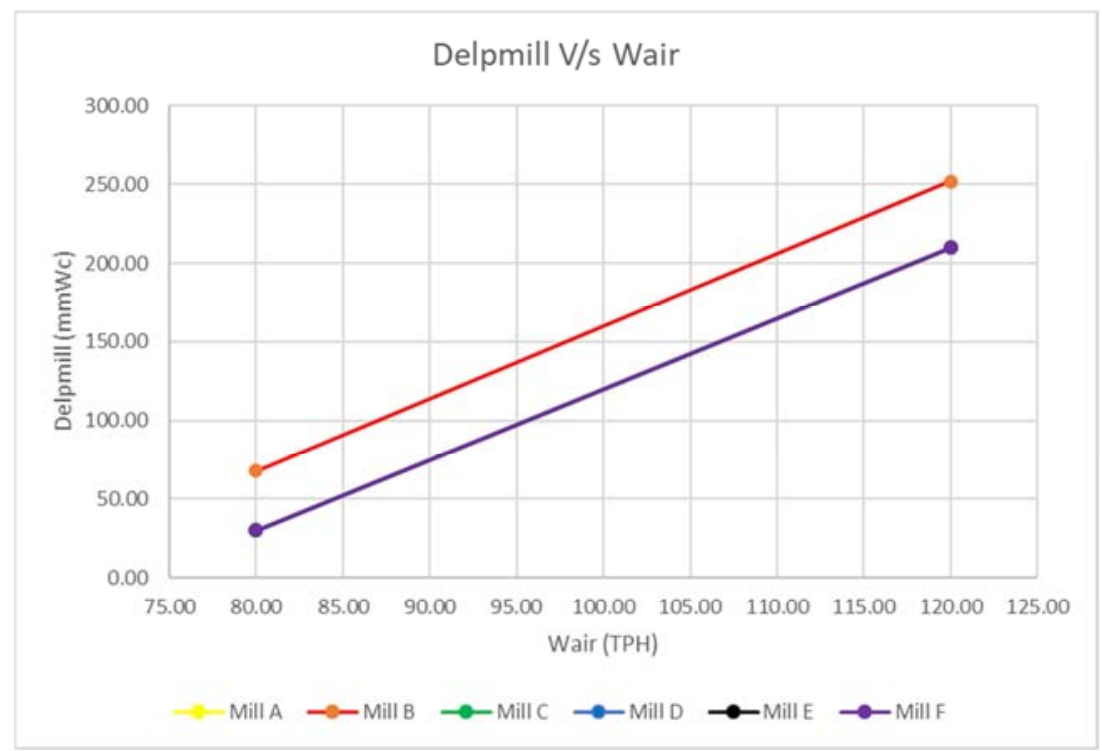

Figure 11. Delpmill V/s Wair curve of mill $A, B, C, D, E, F$.

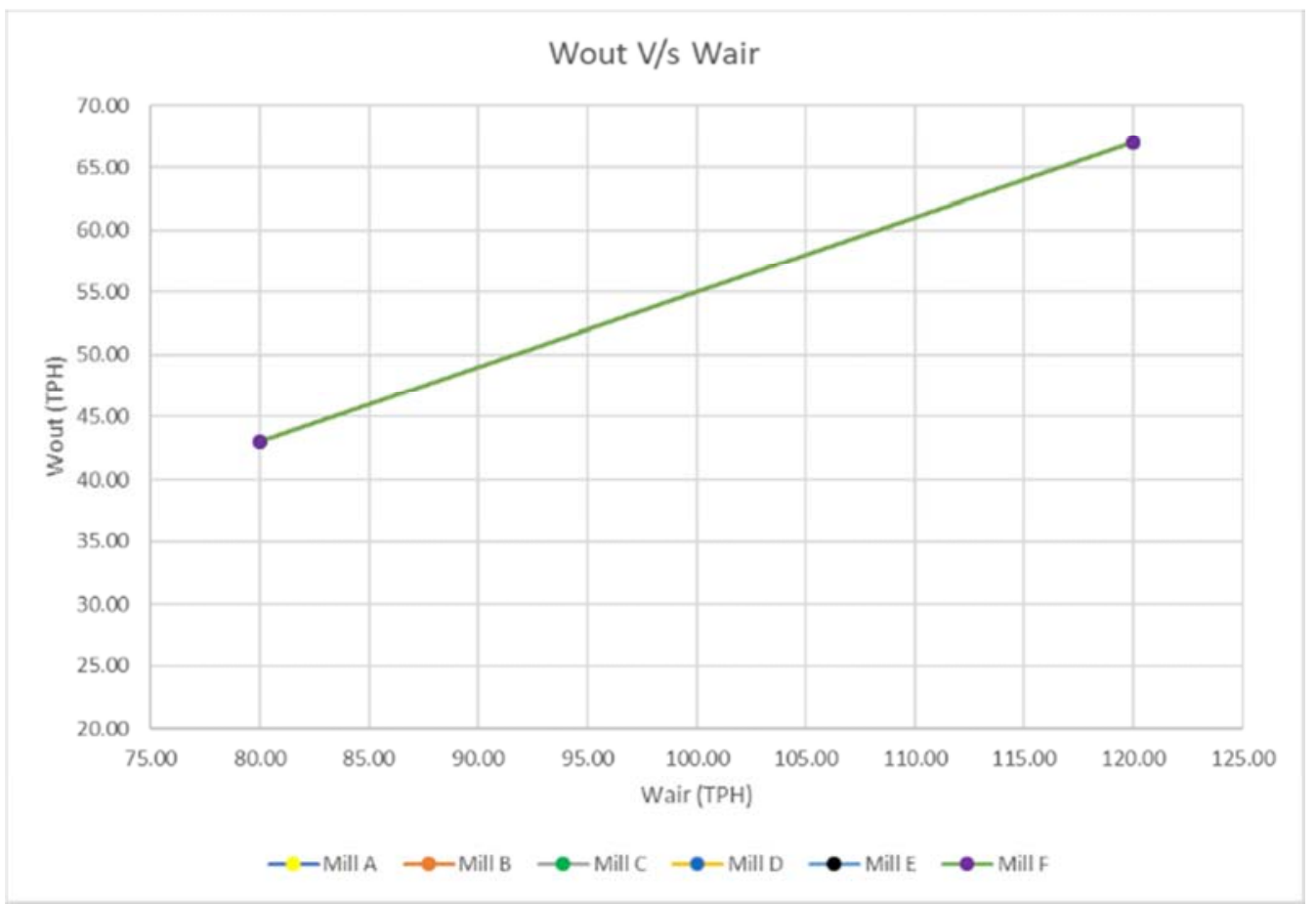

Figure 12. Wout V/s Wair curve of mill $A, B, C, D, E, F$.

\subsection{Case I - No Pulverizer Is Degraded}

The optimized results are compared against the conditions in which all six operating pulverizers are loaded equally with coal. 
Table 5. Comparison of results when no pulverizer is degraded.

\begin{tabular}{llll}
\hline & Optimized & & Equally Distributed \\
\cline { 2 - 4 } & Coal flow (TPH) & DelpMill (mmWc) & Coal flow rate (TPH) \\
\hline Pulverizer A & 58.33 & 145.00 & 58.33 \\
Pulverizer B & 58.33 & 145.00 & 58.33 \\
Pulverizer C & 58.33 & 145.00 & 58.33 \\
Pulverizer D & 58.33 & 145.00 & 58.33 \\
Pulverizer E & 58.33 & 145.00 & 58.33 \\
Pulverizer F & 58.33 & 145.00 & 58.33 \\
Total & 350.00 & 870.00 & 350.00 \\
\hline
\end{tabular}

\subsection{Case II - One Pulverizer Is Degraded}

Degradation is simulated in operating pulverizer B. The optimized results are compared against the conditions in which they are loaded equally.

Table 6. Comparison of results when one pulverizers is degraded.

\begin{tabular}{llll}
\hline & Optimized & Equally Distributed \\
\cline { 2 - 4 } & Coal flow (TPH) & DelpMill (mmWc) & Coal flow rate (TPH) \\
\hline Pulverizer A & 61.40 & 168.00 & 58.33 \\
Pulverizer B & 43.00 & 68.00 & 58.33 \\
Pulverizer C & 61.40 & 168.00 & 58.33 \\
Pulverizer D & 61.40 & 168.00 & 58.33 \\
Pulverizer E & 61.40 & 168.00 & 58.33 \\
Pulverizer F & 61.40 & 168.00 & 58.33 \\
Total & 350.00 & 908.00 & 350.00 \\
\hline
\end{tabular}

\subsection{Case III - Two Pulverizer Are Degraded}

Degradation is simulated in pulveizer B and C. The optimized results are compared against the conditions in which they are loaded equally.

Table 7. Comparison of results when two pulverizers are degraded.

\begin{tabular}{llll}
\hline & Optimized & Equally Distributed \\
\cline { 2 - 4 } & Coal flow (TPH) & DelpMill (mmWc) & Coal flow rate (TPH) \\
\hline Pulverizer A & 66.00 & 202.50 & 58.33 \\
Pulverizer B & 43.00 & 68.00 & 58.33 \\
Pulverizer C & 43.00 & 68.00 & 58.33 \\
Pulverizer D & 66.00 & 202.50 & 58.33 \\
Pulverizer E & 66.00 & 202.50 & 58.33 \\
Pulverizer F & 66.00 & 202.50 & 58.33 \\
Total & 350.00 & 946.00 & 350.00 \\
\hline
\end{tabular}

\section{Distribution of Optimized Coal Flow}

A total coal demand trend over 24 hrs as 15 min blocks is assumed. The distribution of coal among 6 mills are obtained using the optimization model discussed above. The total coal demand trend per block is given in Figure 13.

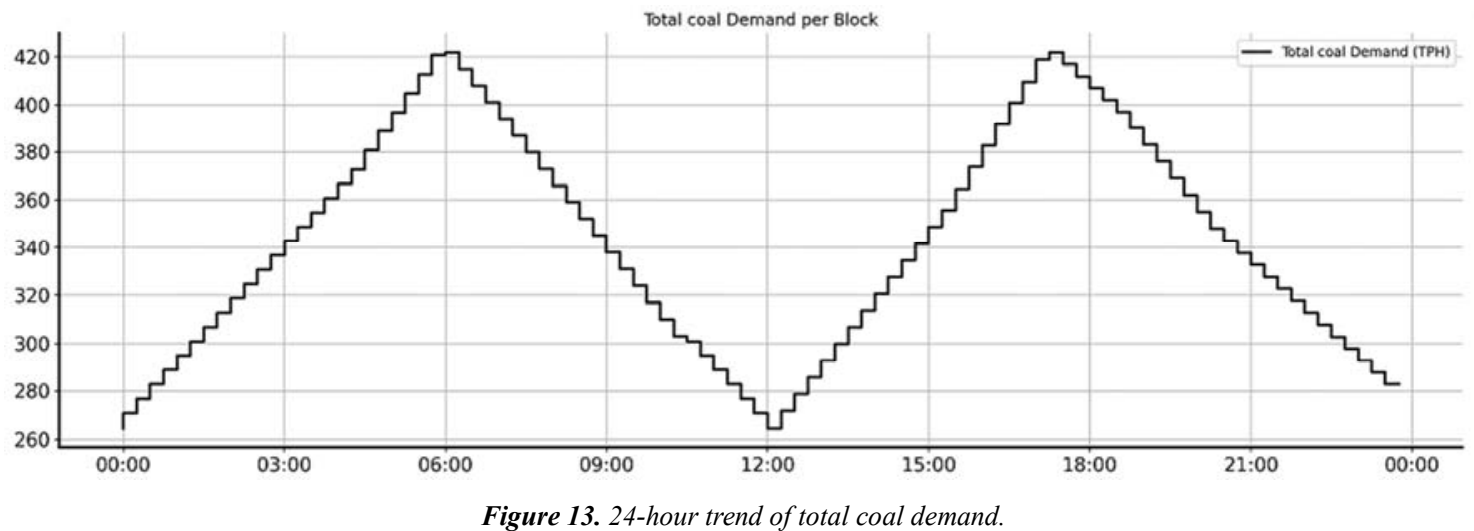

Figure 13. 24-hour trend of total coal demand. 
The optimization algorithm is run on 3 different cases.

1. No pulverizer is degraded.

2. One pulverizer is degraded.

3. Two pulverizers are degraded (Degradation in the pulverizers are not identical).

\subsection{Case I - No Pulverizer Is Degraded}

Figure 14 shows the coal distribution among the six pulverizers when none are degraded. Since there is no degradation, the total coal demand is distributed equally among the six pulverizers.

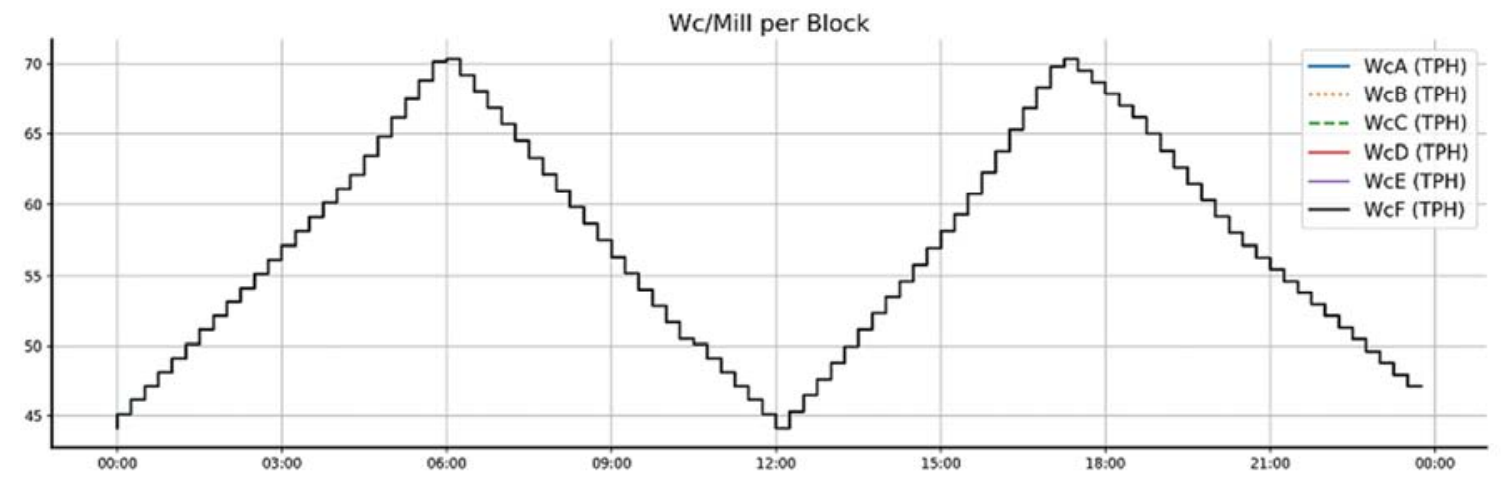

Figure 14. Coal distribution among six pulverizers when no pulverizers are degraded.

Following figure 15 shows the comparison of objective function (total pulverizer DP) over 96 blocks.

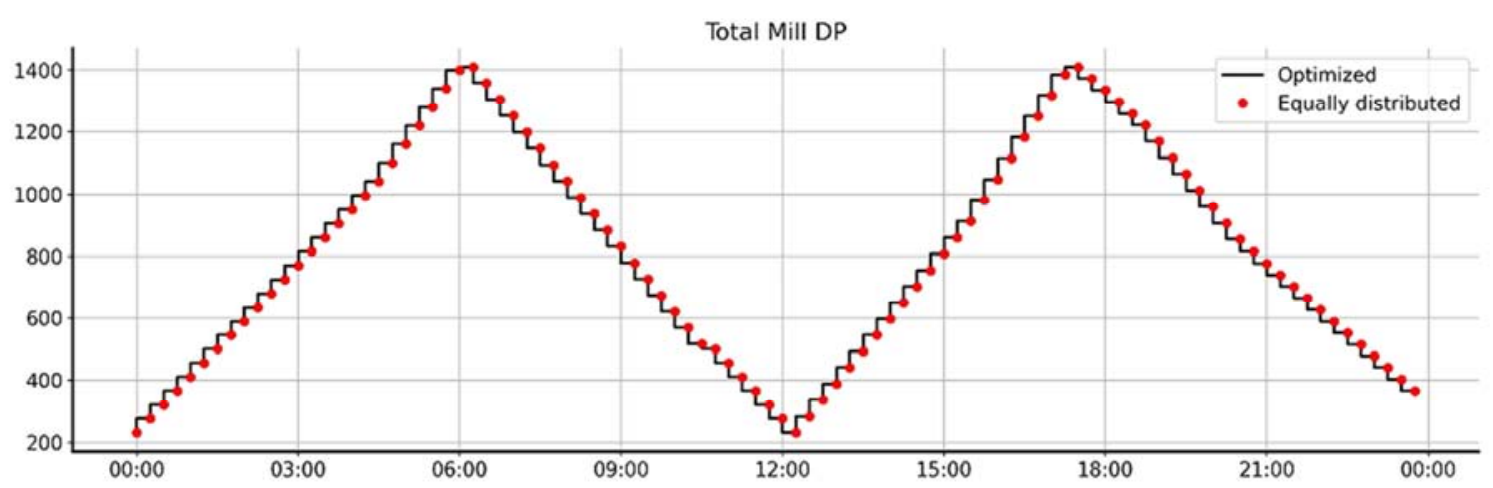

Figure 15. Comparison of objective function over 96 blocks.

\subsection{Case II - One Pulverizer Is Degraded}

Figure 16 shows the coal distribution among the six pulverizers when one pulverizer (pulverizer B) is degraded. Coal is distributed equally among the five non degraded pulverizers and less coal is allocated to the degraded pulverizer.

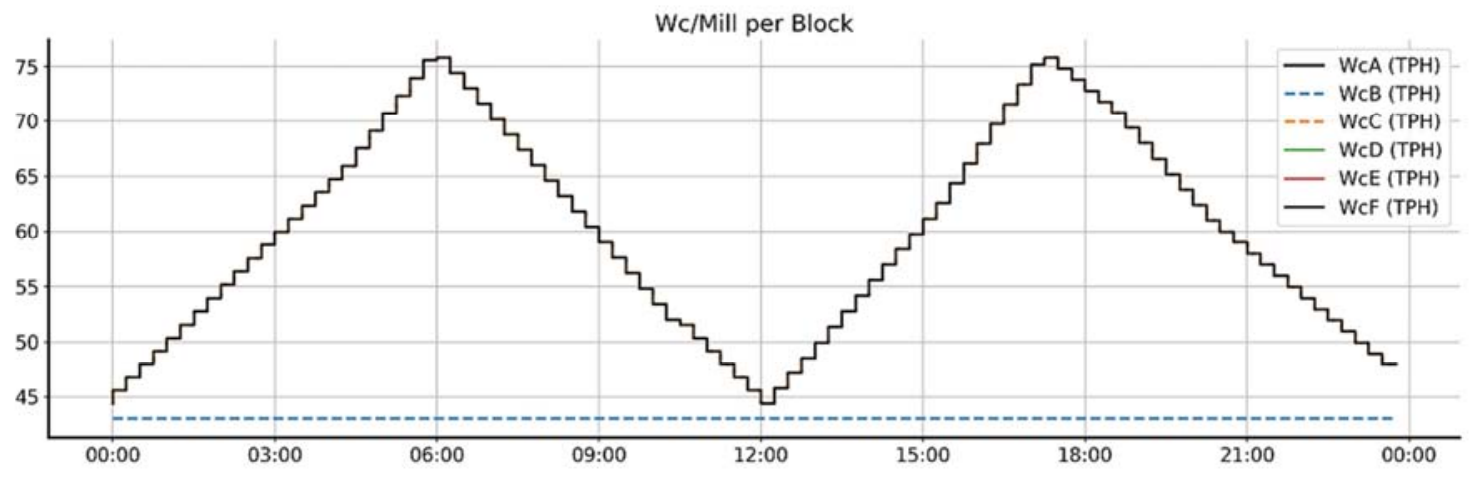

Figure 16. Coal distribution among six pulverizers when one pulverizer is degraded. 
Following figure 17 shows the comparison of objective function (total mill DP) over 96 blocks.

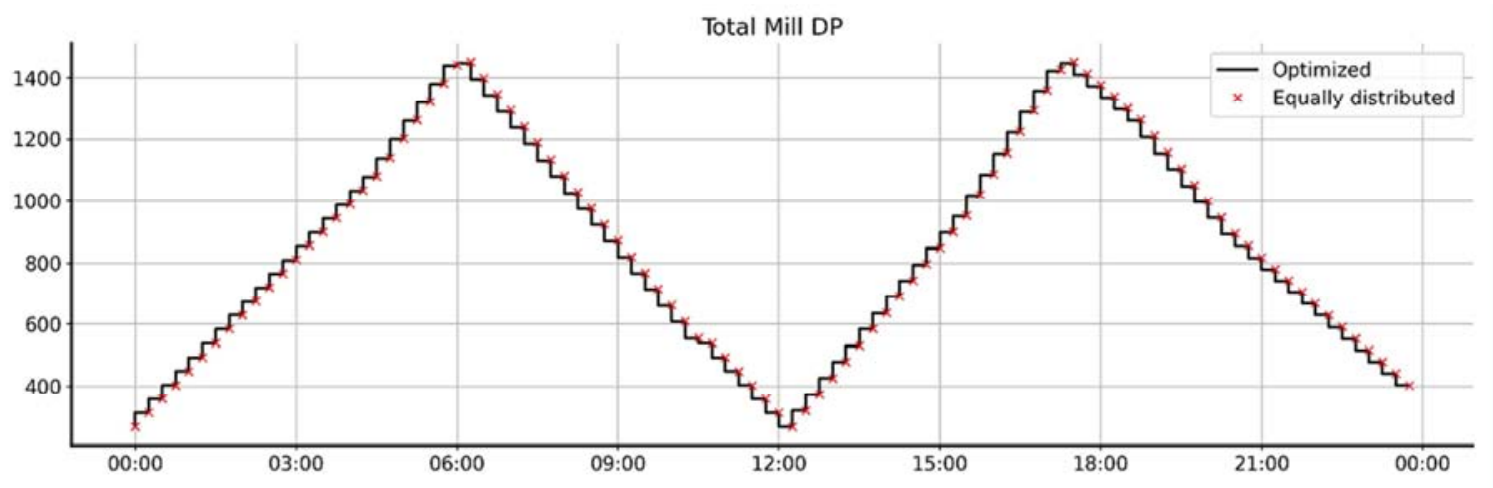

Figure 17. Comparison of objective function over 96 blocks.

\subsection{Case III - Two Pulverizers Are Degraded}

Figure 18 shows the coal distribution among the 6 mills when two pulverizers (pulverizer B \& C) are degraded. Degradation in pulverizer $\mathrm{C}$ is higher than pulverizer B. Coal is distributed equally among the four non degraded pulverizers and less coal is allocated to the degraded pulverizers. Worser the degradation, lesser the coal allocated to that pulverizer. Hence, more coal is allocated to pulverizer B compared to pulverizer C.

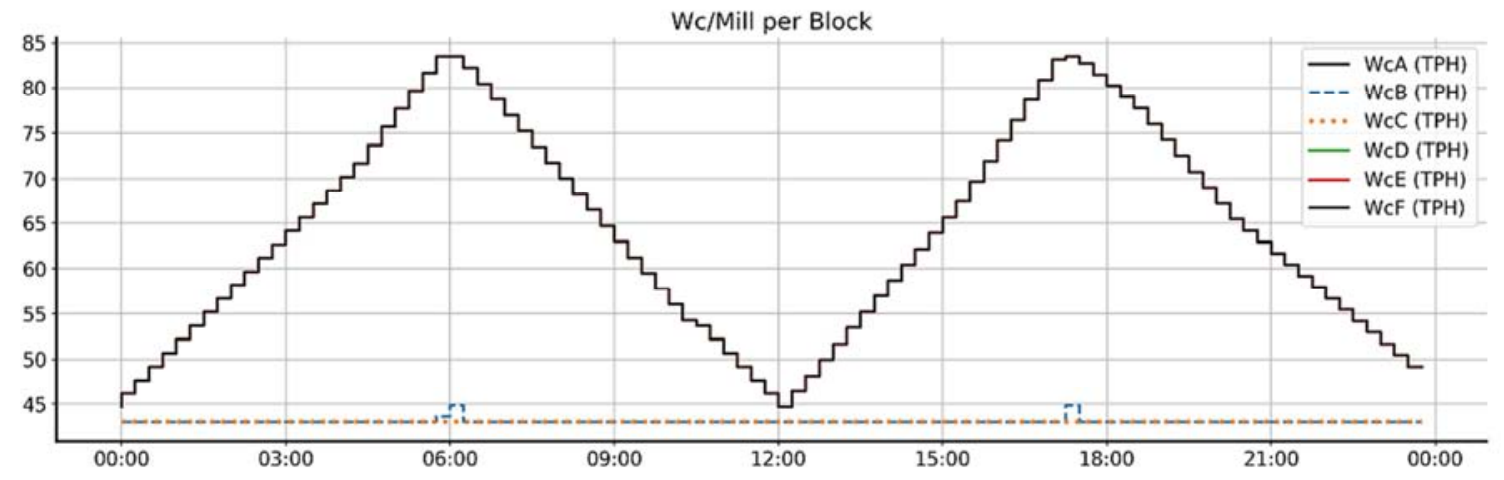

Figure 18. Coal distribution among six pulverizers when two pulverizers are degraded.

Following figure 19 shows the comparison of objective function (total mill DP) over 96 blocks.

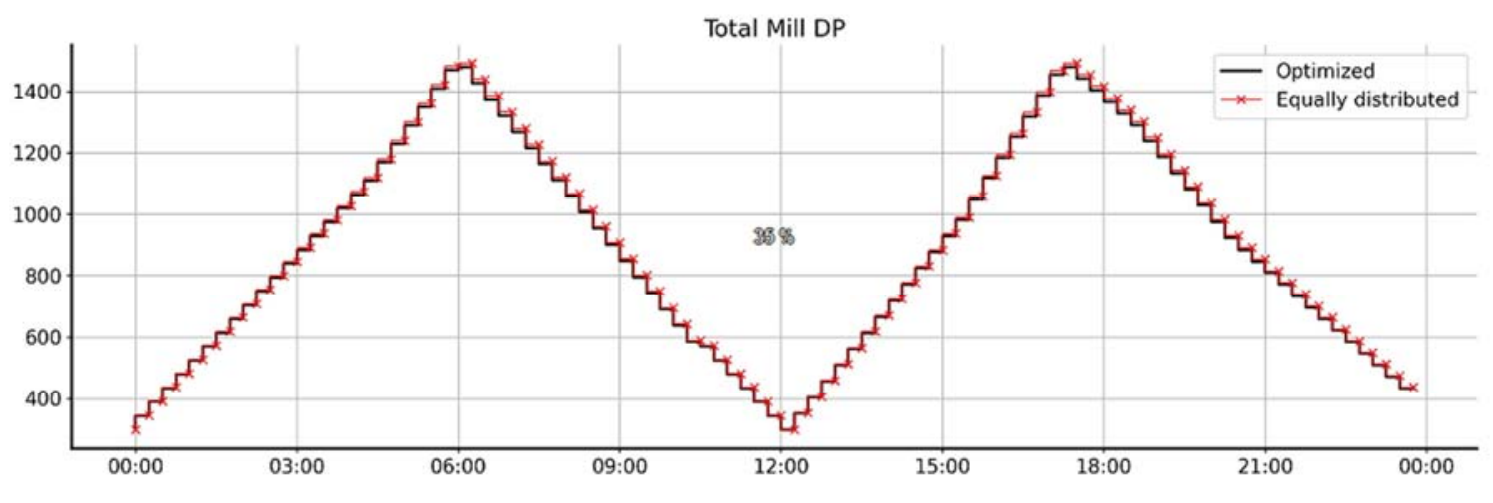

Figure 19. Comparison of objective function over 96 blocks.

\section{Conclusion}

The first principle model-based dynamic simulation of multi variable non-linear model of pulvizer in python environment are developed by determining the parameters obtained by using the moving horizon estimation and reveals the actual open loop performance of the pulverizer for varying differential pressure across it as the major variable parameters and under varying coal flow demand and the constraint of maximum pulverizer loading capacity. Hence, coordinated 
control of all operating pulverizer can be achieved by optimum loading of each pulverizer based on their real operating performance attributed to operating differential pressure across it. This simulation studies also reveals that the actual performance of each of the pulverizer can be considered in the model predictive coordinated control of pulverizer in boiler combustion optimization system.

Hence, the proposed multivariable nonlinear model of dynamic classifier type coal pulverizers reflecting the real operational behaviour of the coal pulverizers will improve significantly the heat rate, NOx reduction, primary air flow, average oxygen demand, unburnt carbon under varying coal flow demand and under the constraint of maximum pulverizer loading capacity to finally achieve the operational flexibility and stability towards higher megawatt load ramp rate of coal fired power generating plant. Future work can also be done to further make the model more realistic by incorporating other factors which impacts the performance of the pulverizers. It is also recommended that all the latest digital control system applied for coal fired steam generators should incorporate similar models as a standard feature of combustion control to address the requirement of flexible operation with higher megawatt load ramp rate.

\section{Acknowledgements}

The authors would like to gratefully acknowledge their respective organizations M/s L\&T-MHI Power Boilers Pvt. Ltd, India and Kalki Communication Technologies Pvt Ltd, India towards designing the model of the coal pulverizer for optimum coal loading and compare the system performance towards process disturbance that form the content of this paper.

\section{References}

[1] Piotr Niemczyk, Jan Dimon Bendtson, Anders Peter Ravn, Palle Anderson, Tom Sondergaard Pedersen,(2012), Derivation and validation of a coal mill model for control, Control Engineering Practice, 20, 519-530.

[2] P Pradeebha, N Pappa, D Vasanthi,(2013), Modeling and Control of Coal Mill, The International Federation of Automatic Control, 18-20.
[3] Xiufan Liang, Yiguo $\mathrm{Li}$, Xiao Wu and Jiong Shen,(2018), Nonlinear Modeling and Inferential Multi-Model Predictive Control of a Pulverizing System in a Coal Fired Power Plant based on Moving Horizon Estimation, Energies

[4] Hwi-Beom Shin, Xin-lan Li, In-Young Jeong, Jong-Man Park, and Soonyoung Lee,(2009), Modeling and Parameter Identification of Coal Mill, Journal of Power Electronics, 700-706.

[5] Haseltine, E. L. and J. B. Rawlings (2005). Critical evaluation of extended kalman filtering and moving horizon estimation. Ind. Eng. Chem. Res. 44, 2451-2460.

[6] Agrawal, V.; Panigrahi, B. K.; Subbarao, P. M. V..(2015), Review of control and fault diagnosis methods applied to coal mills. J. Process Control, 32, 138-153.

[7] Agrawal, V.; Panigrahi, B. K.; Subbarao, P. M. V. (2015), A unified thermo-mechanical model for coal mill operation. Control Eng. Pract. 44, 157-171.

[8] Gao, Y.; Zeng, D.; Liu, J.; Jian, Y. (2017), Optimization control of a pulverizing system on the basis of the estimation of the outlet coal powder flow of a coal mill. Control Eng. Pract., 63, 69-80.

[9] Wu, X; Shen, J; Li, Y; Lee, K. Y. (2014), Fuzzy modelling and stable model predictive tracking control of large scale power plants, J. Process Control, 24, 1609-1626.

[10] Garriga, J. L.; Soroush, M,. (2010), Model predictive control tuning methods: A review. Ind. Eng. Chem. Res, 49, 35053515 .

[11] Zeng, D. L.; Hu, Y.; Gao, S.; Liu, J. Z.(2015), Modelling and control of pulverizing system considering coal moisture. Energy, 80, 55-63.

[12] Cortinovis A., Mercangoez M., and Mathur T., B (2013) Nonlinear coal mill modeling and its application to model predictive control. Control Engineering Practice, 21, 308-320.

[13] Lei, Y.; Yang, B.; Jiang, X.; Jia, F.; Li, N.; Nandi, A. K. (2020), Applications of machine learning to machine fault diagnosis: A review and roadmap. Mech. Syst. Signal Process, 138, 106587

[14] Yong Hu; Boyu Ping; Deliang Jeng; Yuguang Niu; Yaokui Gao; (2020), Modelling of coal mill system used for fault simulation, Energies, 13 (7), 1784.

[15] Bhatt, D.; Dadiala, V.; Barve, J. (2018), Industrial Coal Pulverizer Model Simulation and Parametric Investigation. IFAC Papers online, 51, 115-120. 